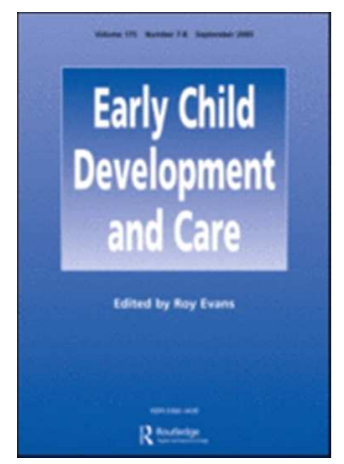

\title{
Evolution of the Early Childhood Curriculum in China: The Impact of Social and Cultural Factors on Revolution and Innovation
}

\begin{tabular}{|r|l|}
\hline Journal: & Early Child Development and Care \\
\hline Manuscript ID & Draft \\
\hline Manuscript Type: & Review Article \\
\hline Keywords: & $\begin{array}{l}\text { China, early childhood curriculum, curriculum reform, local culture, global } \\
\text { influences }\end{array}$ \\
\hline \multicolumn{2}{|l}{} \\
\hline
\end{tabular}

SCHOLARONE ${ }^{m}$

Manuscripts 


\title{
Evolution of the Early Childhood Curriculum in China: The Impact of Social and Cultural Factors on Revolution and Innovation
}

\begin{abstract}
During the last century, early childhood curriculum (ECC) in China has undergone a series of monumental transformations, shaped by the interaction between local cultural and global forces. In this case study, we seek to address two questions: (1) How has the ECC in China evolved and been revolutionised over the past century? (2) How has the interaction between the local cultural and global influences informed the development and changing nature of ECC in China? We critically analyse three major waves of ECC reform in China, with a particular emphasis on the social and cultural forces that have shaped the evolution and revolution of ECC in China. Our analysis reveals the effects of these different forces in inducing change and how they propelled innovative reform of ECC. Furthermore, we deconstruct China's history of adopting and adapting curriculum ideologies and models from other cultural contexts with the opposite concepts of cultural relativism and cultural universalism. The findings suggest three important lessons we could learn from China: (1) teacher education is critical; (2) top-down model does not work; and (3) changing ideas does not necessarily mean changing practices. Last, we offer recommendations for the changes needed to achieve successful innovation in ECC.
\end{abstract}

Keywords: China; early childhood curriculum; curriculum reform; local culture; global influences. 
Early childhood education (ECE) (officially known as 'preschool education' in China) refers to full-day programmes that prepare children, aged from three to six years, for primary education. During the last century, especially over the past four decades, ECE in China has undergone a series of monumental transformations that have been shaped by the interactions between local cultural and global forces. Similar transformations have also been observed in ECE in Hong Kong, Singapore and other Chinese societies (Li, Rao, and Tse 2012). Yet, because the curriculum is the fundamental core of education, we cannot ascertain the quality of ECE in China without examining the nature of the curriculum (Li, Wang, and Wong 2011). Hence, in this case study, we seek to examine two questions. First, how has the early childhood curriculum (ECC) in China changed over the past four decades? Second, how has the local culture interacted with global influences to inform the development and changing nature of the ECC in China? The insights gained from our case study may help other societies reflect on their own ECC reforms and transformations.

Since the introduction of the 'open door' policy in 1978, China has been one of the fastest growing economies in the world. During this time, China's educational system has undergone numerous transformations to better meet the changing demands of society and the global market. The first 'open door' policy was initiated and launched in China by the United States around 1900 to ensure equality of provision among partner trading countries and to support the integrity of the Chinese administration. The 'open door' policy was further conceptualised and then launched in 1978 by the 'chief reform designer' Deng Xiaoping, thereby initiating the process of opening the Chinese economy to foreign businesses wishing to invest in and trade with the country. This policy subsequently spurred a chain of economic transformations in China. 
In addition to economic advancement, China's 'open door' policy led to the introduction of foreign educational ideologies (Zhu and Zhang 2008). Education, in and of itself, is a complex matter, which becomes even more complex when the local culture comes face to face with global influences ( $\mathrm{Li}$ 2005). In welcoming foreign educational ideologies, China's response to the complex interaction between the local culture and the forces of globalisation was to adopt or adapt other countries' curricula and philosophies. Few attempts have been made to develop a uniquely Chinese model that fits local social and cultural conditions (Li and Wang 2008; Liu and Feng 2005; Zhu and Wang 2005; Zhu and Zhang 2008). Persistent random changes over the course of a century have resulted in a Chinese ECC that is a hybrid of Japanese, US, Soviet and Italian curricula and pedagogies.

In this study, we frame our analysis of the transformation of China's ECC around three concepts: evolution, revolution and innovation. We define evolution as a process of development and progress over time; revolution as a process of drastic and far-reaching change in thinking and behaving about a particular phenomenon; and innovation as a product of creating new methods or processes resulting from study, observation and experimentation. These three concepts might be interrelated in relation to the development of China's ECC. As such, to understand the evolution of the ECC in China, we begin by analysing China's social and cultural history in relation to the revolution and innovation of its ECC.

\section{A social history of the ECC in China}

'Social history' refers to a general approach to history that focuses on social structure and social change, social movements, families, urbanisation and mobility (Conrad 2001). In our analysis, we seek to uncover the relationships among political, economic and social processes 
and structures in China, and explore their effects on the early childhood programmes and curricula in China over the last century.

\section{Evolution of the ECC in China}

The first ECC in China. ECE was first introduced in China when the first kindergarten was established in 1903 in Wuhan, the capital of Hubei Province (Zhu and Zhang 2008). However, the ECC was not 'made' in China and the leading personnel came from overseas, with the school principals, teachers and the curriculum all being imported from Japan (Li 2009). Similarly, the first modern Statute of Charter Schools, which proclaimed the Rules of Meng Yang Yuan and Family Education, was closely modelled after Japan's Early Childhood Care and Education and Kindergarten Facilities (Li 2009; Zhu and Wang 2005). At the same time, Western missionaries were setting up large numbers of church kindergartens to promote Christianity and Catholicism. The kindergartens followed the original religious curriculum and assumed a Western outlook on all matters, from building facilities, educational materials and teaching methods to daily routines. Furthermore, the 'May Fourth Movement' (or 'New Culture' movement) reform introduced in 1919 was an anti-imperialist, cultural and political policy that called for the rejection of traditional Chinese culture and the adoption of the Western ideals of 'Mr Science' and 'Mr Democracy'. Accordingly, the reform of the ECC during the 1920s and 1930s was influenced by the cultural changes associated with this movement. In particular, in 1922 during the rule of the Northern Warlords (1912-1927), the educational authorities established the so-called 'Ren-xu School System', which was modelled on the US '6 (elementary) + 3 (junior high school) +3 (high school)' education system, and started learning from the United States, including importing and embracing Dewey's progressive educational theories and practices (Zhu and Wang 2005). 
Accordingly, around this time, a US influenced kindergarten curriculum was widely adopted and became popularised in China (Li 2009).

During the early 1900s, China imported a number of curriculum models from a range of countries including Japan, the US and other Western countries (e.g., Froebel from Germany, Montessori from Italy) (Zhu 2015). However, because these curriculum methods were imported from other countries, they did not fit easily with the prevailing sociocultural conditions in China (Zhu and Zhang 2008). Thus, to address the developmental needs of young children in China, Chinese educators began to seek ways to develop a localised Chinese ECC.

The first Chinese ECC in China. The first experimentation with a Chinese ECC occurred when two Chinese education pioneers, Chen He-qin and Zhang Zong-lin, established the Gulou Kindergarten in 1923 in Nanjing. Initially, Chen and Zhang developed and piloted a localised and culturally appropriate curriculum befitting the Chinese context, which was heavily influenced by the educational ideologies of John Dewey (Zhu 2015), who promoted a more democratic model of a child-centred, play-centred and life-centred learning experience. After a decade of trialling with Western ideas, Chen and Zhang shifted their strategy to developing a uniquely Chinese curriculum, which they termed a 'unit-based integrated curriculum'. Central to this curriculum was the recognition that young children's learning experiences, daily life and activities were valuable sources of learning. This approach thus transformed ECE from the traditional model of an adult-centred, classroom-centred and unauthentic learning experience into a more democratic model of a child-centred, play-centred and life-centred learning experience. Essentially, the new curriculum required a paradigm shift away from adult-centred to child-centred, whereby the active role in the teaching and learning process shifted from the adult to the child. As it was proven to be implementable and practicable in the pilot studies at Gulou 
Kindergarten, this innovative unit-based integrated curriculum was deemed socio-culturally and contextually appropriate, and thus was widely regarded as the first Chinese ECC. Furthermore, the curriculum was hailed as the national standard and was included in the Kindergartens' Curriculum Standards issued by the educational authorities in 1932, and subsequently adopted by most kindergartens throughout China during the 1930s and 1940s. In sum, between the 1920s and 1940s, China witnessed the emergence of a curriculum model that embraced the first innovations of a Chinese ECC (Li 2009; Zhu 2015).

Learning from the Soviet Union. Soon after the People's Republic of China (PRC) was founded in 1949, the new socialist government immediately launched a series of political, economic, social and cultural reforms. As its socialist partner and role model, the Soviet Union naturally became the blueprint for the reform of the Chinese education system (Li 2009). For instance, the school system, curriculum and pedagogy were simply transplanted from the Soviet Union into China without considering their sociocultural appropriateness. Furthermore, to thoroughly eliminate the influence of non-socialist thoughts and practices in schools, ECE in China simply abandoned all of the other formerly adopted curriculum models, including the Chinese unit-based integrated curriculum, US religion-based curriculum and Montessori curriculum, which were replaced by the subject-based curriculum imported from the Soviet Union (Wang and Mao1996).

In the political discourse on socialism in China, education is commonly known as the servant of politics. As the nature of society changed after 1949, so did politics and the education system. For instance, Dewey's educational thoughts and child-centred theories were criticised because they came from the hostile and capitalist United States. The ECE models imported from other Western countries were also abandoned, because they did not serve socialist political and 
policy ideals. The unit-based integrated curriculum developed by Chen and Zhang was also abolished, as it was promoted by the former Chinese government (Republic of China) and deemed to be inappropriate in the context of the new PRC. For China, during this period of political transition, the 'only politically correct curriculum in the world' was considered to be that of the Soviet Union (Li 2009).

Subsequently, in 1952, the Ministry of Education issued the Interim Regulation on Kindergarten and the Provisional Regulation on Kindergarten Curriculum, announcing that the subject-based curriculum with subject teaching was the only legitimate curriculum in China (Li 2009). The teaching syllabi comprised six learning subjects: (1) physical education, (2) language, (3) arts, (4) music, (5) maths and (6) environmental learning. The curriculum reflected the logic and systematic nature of the six disciplines, emphasised the importance of young children's subject learning, valued knowledge and skills and highlighted the roles of classroom teaching and homework learning. As a consequence of this dramatic curriculum reform, the Soviet Union's subject-based curriculum became the only curriculum mode unifying the ECE sectors across the entire country. However, this imported model was short lived as it proved to be unsuccessful in addressing the sociocultural climate of China. In turn, some Chinese educators started to explore a more culturally and contextually appropriate curriculum for the new socialist society, in which young Chinese children had been growing up since 1949 (Li 2009). However, this effort came to a halt when the Cultural Revolution broke out in 1966.

\section{The Continued Saga of the ECC in China}

The years between 1966 and 1976 are regarded as the 'dark age' of ECE in China, as during this time, kindergartens were closed down and young children were sent home with no more opportunities for an early education ( $\mathrm{Li} 2009$ ). The development of a Chinese early childhood 
curriculum was also suspended as, during the Cultural Revolution, all educators were sent to rural or remote areas for 're-education' through labour. However, the dark age was short lived and was replaced by the 'golden era' of ECE in China, when the central government was beginning to re-open the country's doors to the outside world in 1978. Kindergartens were encouraged to develop new curriculum models in the name of curriculum reform as the government and society, which valued knowledge, skills, talent and creativity, jointly wished to reconstruct society through educational reform (Zhu 2015). In 1979, the Ministry of Education issued Guidelines on Kindergarten Education (Draft), which encouraged kindergartens to adopt the subject-based curriculum developed in the 1950s. However, the curriculum was expanded from the original six to eight subjects: (1) daily hygiene, (2) moral education, (3) physical education, (4) language, (5) arts, (6) music, (7) maths and (8) general studies. Published in 1982, the national textbooks for the curriculum encouraged all kindergarten teachers to adopt the new subject model. This initiative was deemed crucial to 'restoring order' in early childhood teaching and learning (Zhu and Zhang 2008). However, the new subject-based curriculum model was similar to that widely practised in primary and secondary schools. Accordingly, kindergarten teachers delivered the teacher-directed subject teaching in a traditional, primary school education-driven way, and kindergarteners were treated and trained as pupils in primary schools. The problem became more serious when many Chinese parents began expecting their children to 'win at the starting line'. Nonetheless, the economic reforms dramatically transformed Chinese society and initiated many changes to ECE. As a result, it seemed that the subject-based curriculum model borrowed from the Soviet Union was no longer suitable in the context of the rapidly developing Chinese economy. Subsequently, another round of curriculum reform 
occurred. This time, the Chinese government and the people once again shared the same goal of learning from the United States (Zhu 2015).

Learning from America. The 'open door' policy legitimised China's efforts to establish social, economic and political connections with the outside world (Zhu 2015). Most notably, in the education realm, the 'open door' policy led to the introduction of other Western theories on child development and associated pedagogical practices. However, the efforts to reform early childhood education in China were still rooted in a top-down model, led by the central government (Li, Wang, and Wong 2011; Liu and Feng 2005).

The first formal wave of curriculum reform under the new top-down approach commenced in 1989 when the National Education Commission issued Regulations on Kindergarten Education Practice - Trial Version. To extend this reform, in 2001, the Ministry of Education released the supplementary Guidelines for Kindergarten Education Practice - Trial Version. These two policy documents jointly advocated the implementation of ECE ideologies and practices that aspired to 'face the world, face the future, and face modernisation' (Zhu and Zhang 2008, 174). In their post hoc review, Liu and Feng (2005), the ECE reform leaders, stated that this wave of curriculum reform was 'an ideas revolution', promoting successfully five major ideas: (1) respecting children, (2) engaging children in active learning, (3) teaching for individual learning needs, (4) emphasising play-based teaching and learning and (5) teaching and learning through daily life in kindergartens. In a critical review, Zhu and Zhang (2008) summarised the five major goals of the curriculum reform as follows: (1) highly valuing child-initiated activity; (2) paying attention to individual differences; (3) providing play as a basic activity; (4) promoting an integrated curriculum; and (5) emphasising the process of learning and activity. Unfortunately, these goals were not consistent with the traditional values advocated by 
Confucius, which emphasise collectivist-oriented goals, such as conformity and child discipline (Li et al. 2011).

Nonetheless, the new document on ECC regulations was immediately and widely disseminated throughout the country, and curriculum reform was implemented at all administrative levels and in all kindergartens. Zhu and Zhang (2008) observed that this reform adopted theories and practices from other cultures, especially those from the United States. This move was not surprising, as the United States was considered a leading country, so it naturally became the model of learning for China. In addition, at this time, it was politically correct to learn from the United States, as China was attempting to catch up with the US in terms of economic and educational development. However, espousing progressive ideologies from the United States proved difficult for Chinese educators, as they were neither trained nor ready to change their familiar Chinese-based practices ( $\mathrm{Li}$ et al. 2012). For example, the traditional values of obeying authority and upholding unity were contrary to the new goal of establishing a democratic and equilateral relationship between the teacher and the individual child. Furthermore, the new regulations were not accompanied by systematic teacher training or practical guidelines, which resulted in kindergarten teachers' having little guidance concerning how to implement the US-inspired ECC (Li et al. 2011).

Recognising the need to provide more guidance to practitioners on implementing the US modelled ECC, in 2001 the Ministry of Education issued Guidelines for Kindergarten Education Practice. The guidelines took into consideration the gap between progressive ideas and reality and tried to bridge this gap by identifying a middle ground between the two (Li et al. 2012). The guidelines also specified five learning fields (health, language, society, science and art), and stated that each field should be taught in sufficient depth (Zhu and Zhang 2008). In each learning 
field, curriculum experts further developed the syllabus, teaching strategies and materials to enhance their practicability and workability. This change was regarded as an improvement (or compromise) and thus was warmly received by practitioners and ECE scholars in China (Li et al. 2012; Zhu and Zhang 2008).

Furthermore, Western curriculum approaches, such as the Project Approach (US), Reggio Emilia (Italian) and Montessori (Italian), have been widely adopted and localised in contemporary China (Li 2005). In addition, early childhood educators have developed their own localised curriculum models, such as the theme-based integrated curriculum developed by Zhu in Shanghai (the largest city in China), which is a progressive, localised education approach (Zhu and Zhang 2008), and the story approach to integrated learning (SAIL) developed by Li (2004), which is a postmodern narrative curriculum ( $\mathrm{Li}$ et al. 2012). The development of the school-based curriculum has also become a trend in recent years. Chinese kindergartens have broken the boundaries between the subject-based and theme- or unit-based curricula by developing a school-based curriculum that blends curriculum modes, such as combining a theme-based integrated curriculum with an early trilingual immersion programme to form a new 'trilingual immersion integrated curriculum' (Li 2005). This wave of curriculum reform is ongoing in China. As a result of China's continuous efforts in experimenting with various curriculum models, its educational approaches have become more diverse and aligned with the increasingly open and diverse society (Zhu and Zhang 2008). Nonetheless, although from an historical perspective the curriculum revolution has been influenced by the sociocultural circumstances, this does not mean that it is problem free. 


\section{A Social History Perspective on ECC Reforms in China}

Heavily influenced by China's ongoing social transformation, the ECE reforms can be characterised as reflecting the interactions among related political, economic and societal changes. Over the past century, the social experimentation with the ECC has produced three major waves of ECC reform that can be divided into three distinct periods: the 1920s-1930s, 1950s-1960s and the 1980s to the present (Zhu and Zhang 2008). All of the periods of reform have occurred as a natural response to major social changes rooted in different causes: the reforms during the 1920s-1930s were influenced by the cultural changes associated with the 'May Fourth Movement' (1919), the reforms during the 1950s-1960s were a response to the political changes associated with the founding of the 'New China' (1949) and the latest ECC reforms were triggered by the economic factors associated with the implementation of the 'open door' policy in 1978 (Li 2009). These different waves suggest that the ECC reforms in China have been sensitive to social change. However, although sensitivity is a critical consideration in ECC reform, compatibility must also be factored in if a reform is to be successful. Unfortunately, in the case of China, the imported curricula were not compatible with the developmental needs of Chinese children or their teachers' professional knowledge. Cultural incompatibility has been a noticeable issue in China's curriculum reforms (Li et al. 2012).

\section{A Cultural History of the Early Childhood Curriculum in China}

Culture is a symbolic social dimension that shapes our perceptions, attributions, judgements and ideas of the self and others (LeBaron 2003). Like an 'underground river' that runs through our lives and relationships, culture is susceptible to change, and at times unconsciously and powerfully affects how we make meaning and enact our sociocultural identities. By 'cultural history', we mean a general approach to history that looks at cultural interpretations of historical 
experience, with a focus on historical events that either affect or reflect the processes and products of cultural change. To understand the cultural history of the ECC in China, we next examine how and why the 'Chinese hybrid culture of ECE' (Wang and Spodek 2000; Zhu and Wang 2005; Zhu and Zhang 2008) was formed through the interactions and interconnections between three distinct cultures, namely, traditional Chinese culture, communist (or politically correct 'socialist') culture and Western culture (Wang and Mao 1996; Wang and Spodek 2000). Yet, these interconnected forces have not always led to consistent outcomes, as they have resulted in both cultural collisions and fusions.

\section{Shapers and Movers of the ECC in China: A Hybrid of Three Cultural Threads}

In the past century, the ECC in China has undergone three major waves of reform amid the associated cultural changes. In the third and most recent wave (since the 1980s), the 'open door' policy has resulted in the importation of the key constructivist-oriented educational theories from the West, such as those of Dewey, Montessori, Bruner and especially Piaget and Vygotsky (Zhu 2015). However, these 'imported' ideas have posed significant challenges to the original ECC model in China, which was 'imported' from the Soviet Union. In addition, the thoughts of modern Chinese educationalists (e.g., Chen He-qin and Zhang Zong-lin) have been brought to the fore once again. The three cultural threads, Western ideology, the Soviet model and Chinese cultural ideology, have interacted and become intertwined during the process of curriculum reform and the development of Chinese kindergartens. Unfortunately, in the process, cultural collision has been unavoidable.

Traditional Chinese culture is rooted in Confucianism, which has had a far-reaching influence on China and other Asian societies since ancient times. The nature of Confucianism has evolved over the past 2000 years. It was first accepted as a religion emphasising virtue and 
relationships, and adopted in the Qing Dynasty. When it gradually evolved into a philosophy, Confucianism expanded to include a focus on desirable child behaviour. For instance, one area of Confucian philosophy emphasises impressing on young children a sense of conformity, discipline, self-control, effort and academic achievement (Chen 2007; Rao, Ng, and Pearson 2010). Not surprisingly, Chinese parents have traditionally held high expectations for their children's early learning and academic achievement (Chen 2005; Li et al. 2012). Furthermore, traditional Chinese culture places high value on group-oriented or social unit-oriented rather than individual-oriented activities, and promotes extrinsically-motivated, as opposed to intrinsically-motivated, activities (Liu and Feng 2005; Tobin 2005). Accordingly, Chinese parents and teachers tend to value drilling, memorising and disciplining rather than creativity, understanding and individual freedom ( $\mathrm{Li}$ et al. 2012). These traditional cultural characteristics have greatly influenced Chinese educational ideas. For example, Chinese teachers emphasise expression, diction, memorisation and self-confidence in speaking and performing in early language education ( $\mathrm{Li} 2014$ ). In turn, it is not surprising to find that young Chinese children have to learn how to deliver long speeches flawlessly, and recall songs with many verses ( $\mathrm{Li}$ and Rao 2005). This cultural influence has been so strong that although indicating their acceptance of imported curricula and pedagogies from other cultures, Chinese teachers still practice traditional pedagogical methods that are strongly influenced by deeply ingrained Confucian views (Li et al. 2011; Wang and Spodek 2000; Zhu and Wang 2005).

To meet the needs of a communist society, the socialist government imported the curriculum model of the Soviet Union in the 1950s. Because Soviet communist culture valued planning and unity, the ECC in China correspondingly favoured unified content and schedules (Wang and Spodek 2000). The associated curriculum emphasised a teacher-centred pedagogy 
that needed to be planned and delivered according to the scientific and logical characteristics of each content subject. Accordingly, early childhood/kindergarten teachers were required to systematically teach children different content subjects using purposeful and planned activities (Zhu and Wang 2005). Although the ECC models adopted in China at that time were subsequently rejected, there was some compatibility between traditional Chinese culture and the communist culture as both valued centralised administration, planned systems, learning outcomes, defined goals and teacher instruction (Zhu and Wang 2005). Thus, the introduced reform was implemented smoothly.

Other cultural forces have also made headway in China since the 'door' was opened to the outside world in 1978. American culture has undoubtedly become a popular, dominant force. Along with commercialised products, such as McDonald's, Coca Cola and Hollywood movies, American values, social beliefs and educational practices have also been imported into China. These influences have brought about the third and latest wave of ECC reform (since the 1980s) in China. The major task of this reform was to promote US influenced educational practices, such as implementing a play-based curriculum and practising child-centred instruction (Liu and Feng 2005). Contrary to communist culture, this 'new' culture tended to view the ECC as key to promoting individuality, autonomy, problem solving, friendship and cognitive development in children (Zhu and Zhang 2008). In this newest wave of curriculum reform, many Chinese kindergarten teachers have attempted to change their teaching style from being teacher-directed to child-centred, even though they are used to culturally rooted 'old' strategies and methods. In addition, most parents value teacher-directed instruction rather than child self-exploration as a pedagogy. Although Chinese teachers reported that they believed in Western ideas and practices, they still practised the traditional methods of teaching young children, resulting in an inevitable 
belief-practice gap (Li et al. 2011). This belief-practice gap suggests that Chinese kindergarten teachers may have developed pedagogical tension as a result of cultural collision. Possibly, the best outcome of this kind of cultural collision is a cultural fusion that naturally and gradually interweaves all of the cultures involved (Chen, $\mathrm{Li}$, and Wang in press).

\section{Cultural Relativism versus Cultural Universalism}

Chinese traditional/communist culture and US culture are radically different, and may even be considered polar opposites in several basic ways. The differences between the two cultures can be classified as reflecting five major dimensions: (1) tightness (Chinese/communist) versus looseness (US); (2) collectivism (Chinese/communist) versus individualism (US); (3) vertical (Chinese/communist) versus horizontal (US); (4) passive (Chinese/communist) versus active (US) and (5) suppression (Chinese/communist) versus emotional expression (US) (Triandis 2000). As cultures affect the ways in which individuals 'name, frame, blame, and attempt to tame' conflicts (LeBaron 2003), whether and how these remarkable cultural differences promote cultural conflict is indeed an open intellectual question. For instance, influenced by the traditional Confucian-driven culture, Chinese people prefer to perceive the world through the lens of harmony rather than conflict, thereby viewing cultural collision as a process of cultural fusion and harmonisation. Western culture, however, tends to perceive certain discrepant cultural interactions as conflicts (LeBaron 2003). To resolve these cultural conflicts/collisions, two contrasting frameworks have been widely applied, namely cultural relativism and cultural universalism.

Cultural relativism. This framework is based on the idea that every culture has its own value system and uniqueness, and thus there is no one universal culture (Li 2007b). The framework presupposes an epistemological rather than a moral concept that individual beliefs, 
practices and standards are culturally specific, and therefore should not be considered universal (Tobin 2005). Following this logic, it is then intellectually and methodologically unsound to evaluate other cultures using the assumptions and categories of our own culture, and vice versa. The underlying assumption of cultural relativism is that there are many different cultures, all of which should be respected as equally valuable. For instance, from the perspective of cultural relativism, an ECC derived from the culture and quality standards of the US is neither universal nor free of cultural assumptions, but instead reflects the values and concerns of a particular body of people (i.e., Americans) at a particular place and time (Tobin 2005).

Cultural universalism. This framework is based on the idea that there are universal values, and a 'best culture' that should be followed by all nations (Li 2007b). For example, some people in Asian and African countries tend to believe that European/American culture and values are more advanced, and perhaps even the best in the world. Consequently, some social reformers and policy leaders who are eager for social success strongly wish to replace their own 'disadvantaged' cultures with values imported from the global super power of the United States. Here, the underlying assumption is that US culture is superior to the rest (Li 2007b). From this perspective, if a culture was to be globalised, it would most likely be that of the United States. However, this is a typical view reflecting European/American cultural centrism, which could even be regarded as cultural colonialism. Thus, neither cultural universalisation nor cultural colonialism is ideal. In contrast, both cultural relativism and postmodernism strongly advocate cultural equality, pluralism and mutual respect.

Due to their enthusiastic reception of the outside world, Chinese societies, especially mainland China and Hong Kong, have been inevitably engaged in the processes of cultural globalisation and universalisation. Various European and American curricular and pedagogical 
models have been imported, such as the Project Approach, Montessori curriculum, Reggio Emilia, High Scope, Whole Language Approach and, in particular, the US-derived framework of developmentally appropriate practice ( $\mathrm{Li}$ et al. 2012). Many Chinese scholars and reform leaders tend to believe that these imported curricula and pedagogies are exemplary, and thus should be adopted. However, in doing so, they have not taken the social differences into consideration or acknowledged the contextual dependence and limitations of the imported programmes and paradigms (Li 2007b). In addition, the ECC reform in China has turned into a form of 'total Westernisation', aimed at replacing the existing curriculum with the imported models. Over the years, many kindergarten directors and teachers have attempted to adapt these models, but some have failed (Zhu and Zhang 2008). The failure has been due to the typical 'cultural universalism' approach underlying the changes, resulting particularly in Chinese teachers' believing in imported ideas, but not being able to implement them with authentic fidelity (Liu and Feng 2005). Consequently, a policy-practice gap and a belief-practice gap can be detected (Li et al. 2008).

Some international observers of ECE development in China have offered recommendations for addressing these two gaps. For instance, Tobin (2005) analysed ECC reform in China and concluded that educational authorities were using reform as a strategy to cope with the challenges associated with globalisation and economic development, and subsequently suggested that Chinese people should develop their own system of ECE on their own terms, and in ways that respect their own culture, while welcoming guidance from the United States. Coincidently, Li (2007b) conducted a critical review of the ECC reform in China and concluded that the reform leaders have embraced cultural universalism. He highlighted that the differences between Chinese traditional culture and Western culture have given rise to the conflict that has affected the implementation of ECC in China. Specifically, traditional Chinese culture values unity, 
collectivism and a subject-based curriculum model, all of which run counter to curricula that are built on a culture of individualism. In addition, Chinese parents' traditionally high expectations and demands for academic achievement challenge child-centred and play-based curricula (Rao et al 2010). Li (2007b) further asserted that there was no high-quality curriculum that could be effectively adopted from other cultures. As such, when importing a curriculum from another culture, it is crucial that educators and policy makers consider the culturally embedded nature of such curriculum, and identify and resolve local realities first.

To follow up on his conclusions about the development of ECE in China, Li (2007a) proposed a new theoretical framework to characterise the ECC reforms. Termed the 3CAPs, the framework is divided into three parts: (1) culturally appropriate practice (CAP1): the reform should be sensitive to Chinese social ecology and culture, and should not be overly dependent on European/American ideas; (2) contextually appropriate practice (CAP2): China should not implement a single quality standard as it faces considerable regional differences, especially those between rural and urban areas, and between eastern and western regions, and as such, its ECC reformers should make the curriculum models contextually appropriate; and (3) individual child appropriate practice (CAP3): Chinese children in different areas may differ with respect to local culture, schooling history, and family background. Li (2007a) proposed that ECC reformers in China should also acknowledge these individual differences, and develop the curriculum accordingly. Nevertheless, our analysis indicates that the ECC reforms in China appear to be irreversible, and have had far-reaching effects. It is clear that ECE in China has been strongly influenced by the recent sociocultural changes and that a hybrid of traditional, communist and Western approaches has emerged through the process of sociocultural experimentation (Li 2007a; Zhu and Wang 2005; Zhu and Zhang 2008). Based on these findings, we now reflect on the 
lessons learned from the current reform of ECC and its implications for the future development of ECE in China.

\section{Current ECC Reform in China: Lessons Learned and Implications to be Considered}

China began opening up to the outside world in the early 1980s, and has since spearheaded reforms in all areas of society, including ECE (Liu and Feng 2005). Although the reform of the ECC began spontaneously in the early 1980s, it was led by a top-down model, thereby yielding little success among the practitioners directly involved. We now reflect on the lessons learned from this particular kind of reform and elaborate its implications for the future development of ECE.

\section{Lessons Learned from the Current ECC Reform in China}

Teacher education is critical to success. As they are directly responsible for the implementation of the curriculum, teachers play the most crucial role in the success of curriculum reform (Chen et al. in press). Therefore, reform leaders should consider Chinese teachers' levels of professional knowledge. Specifically, a successful reform must start with effective teacher training programmes, as the curriculum reform would be ineffective if the teachers were not able to deliver it appropriately. For example, Chinese teachers have been used to subject teaching and a subject-based curriculum for decades. Since 1989, the educational authorities have requested that teachers deliver play activities and an integrated curriculum, yet they have received no formal training, and thus are utterly unprepared for this paradigm shift in pedagogy (Li et al. 2011). This gap between teachers' abilities and the qualifications required by the new curriculum model has thus resulted in the curriculum reform being largely unsuccessful. At best, the reform has only been partially successful as it has solely changed the basic ideas of ECE. Although teachers have been exposed to and acquired more knowledge about the theories 
and ideas concerning early childhood learning and teaching, such knowledge does not automatically and successfully translate into daily practice (Chen et al. in press). This has led to two noticeable gaps, namely, the policy-practice gap and the belief-practice gap (Li et al. 2011). Furthermore, the outcomes of ECE reform have placed high demands on teachers, who realise that they lack knowledge and guidance of how to deliver imported curriculum models. This reality has led to situations in which effective teachers leaving the teaching profession and being replaced by unqualified teachers. This typical 'bad money drives out good' phenomenon has been widely observed in China in the past decade (Li 2013), which suggests that teacher training should be emphasised, well planned and delivered before any curriculum reforms are to be executed.

Top-down model did not work. Like the governance in China, the most recent curriculum reform was centralised, hierarchical and bureaucratic. Because an administrative top-down method was used, policies and regulations were introduced without any consultation with or consideration of frontline teachers. This has subsequently led to a division between those involved in initiating the reforms and those expected to carry them out (Liu and Feng 2005). Neither teachers nor teacher-educators were prepared for the most recent curriculum reform, yet they were requested to implement the changes overnight. Consequently, they lacked the motivation to adjust practice because they had not been consulted (Liu and Feng 2005). In turn, the top-down approach to implementing reform has failed to empower teachers with the knowledge and skills necessary to bring about change in their practice. In contrast, a bottom-up approach would build transparency and accountability, although not without difficulties due to the existing hierarchical social structure. Thus, neither a top-down nor a bottom-up approach is suitable for reforming ECE in China. The best option seems to be the application of a hybrid 
approach that combined the advantages of both (Li et al. 2011). For example, there are three dimensions to the reform of ECE: structure, process and values (Liu and Feng, 2005). It is fairly easy to change the curriculum structure using a top-down approach, whereas changing the teaching process requires cooperation through a bottom-up approach. Moreover, a bottom-up approach would have a better chance of promoting an understanding of what the intended reform and changes were all about, and how they may be implemented. The third dimension concerns changing the values or culture already embedded in the ECE classroom (Liu and Feng 2005). In short, a hybrid of the top-down and bottom-up approaches would provide a more practical model for pursuing a successful curriculum reform in China.

Changing ideas does not necessarily mean changing practices. The ECC reforms that have been implemented since 1989 have indeed marked an 'ideas revolution'. The most significant effect of the reforms has been the wide distribution of modern educational ideologies on teaching practice, child development, and student learning among practitioners (Liu and Feng 2005).

Reform leaders have attempted to change teachers' daily educational behaviours and to reconstruct the curriculum model by transforming their educational ideas about how young children learn and thus how they should teach. Consequently, this educational revolution has promulgated new educational ideas among Chinese teachers (Liu and Feng 2005). However, moving from ideology to practice has been proven challenging for teachers. Thus, it is not surprising to find the existence of a wide gap between teachers' beliefs and practices. This gap may have been a reasonable consequence of the top-down curriculum reform in 1989. The real problem is that the reform focused more on transforming educational ideologies, and less on creating the conditions that would support and realise these ideas (Liu and Feng 2005). This latter issue has effectively left the question of 'how to' for teachers to explore at a practical level. 
However, the teachers have neither the expertise in nor the experience of the different kind of teaching based on Western ECE practices (e.g., High Scope, Reggio Emilia). Accordingly, they fall back on their past experiences (often culturally ingrained) and skills to deliver these new ideas, resulting in a belief-practice gap between pedagogical ideas and actual practice.

\section{Implications for the Future Development of an Innovative ECC}

The ECC reform in contemporary China has gradually progressed since scholars at Nanjing Normal University began to explore the 'new integrated curriculum' models in the 1980s. However, more curriculum studies are needed to develop innovative ECC models in the following domains.

Theoretical understanding of the ECC. Psychology, philosophy and sociology are the theoretical foundations of curriculum development. It is important that Chinese scholars identify culturally relevant theories to further their understanding of the complicated relationships among child-centred ideologies, especially in the areas of play, learning, curriculum and child development in the early years. This knowledge will help to guide the further development of a Chinese ECC.

Studies on curriculum objectives and contents. The curriculum objectives need to be reviewed and revised to make them more culturally and contextually appropriate, such as by using the 3CAPs approach (Li 2007a). The new curriculum objectives should also match the developmental needs of Chinese children in the $21^{\text {st }}$ century. In addition, Chinese ECE scholars should explore more workable curriculum models for delivering learning and teaching activities in culturally and developmentally meaningful ways. Furthermore, the curriculum content should be chosen according to the objectives of the Chinese curriculum and any new curriculum models. 
Studies on school-based curriculum development ( $S B C D)$ and evaluation. China has been promoting SBCD since 2000, although the teachers have not been adequately prepared for this challenge. Recently, Chinese teachers have been upgrading their qualifications to the degree level, and have thus become more qualified to conduct SBCD in their kindergartens. Some new methods, such as learning portfolios and documented observations, have also been advocated recently, although teachers still need more hands-on training and professional guidance. The paradigm for evaluating the Chinese curriculum has shifted from a static, goal-orientation to a dynamic, process-orientation, although the traditional orientation has been on subject matters. This shift is encouraging as it will provide a wider range of avenues for evaluating the effectiveness of a curriculum.

Studies on new curriculum models. Chinese ECC experts and early childhood educators are working collaboratively to develop a unique fusion of well-known curriculum models such as the Project Approach and Chinese pedagogy (Chen et al. in press). Rao et al. (2010) found that the preschool pedagogy in Hong Kong was also a fusion of traditional Chinese beliefs and contemporary notions of appropriate practice. Because ECE in China is neither formal nor compulsory, the transition to school has become an important theoretical and practical issue that needs to be addressed. Chinese scholars have studied this topic from the perspectives of curricular and pedagogical continuity ( $\mathrm{Li}$ et al. 2011). However, more studies are needed to develop socio-culturally and contextually appropriate curriculum models that can facilitate the best transition from kindergarten to formal schooling for young children.

\section{Conclusion}

Chinese scholars have been pursuing the best models for China's ECC development for decades. Their original strategies involved imitating, importing, transplanting, and emulating, 
reflecting the humility and humaneness of the Chinese and their culture. In the past century, compared to more advanced societies, such as Japan, the former Soviet Union and the United States, China has been in a disadvantageous position due to its political, economic and social development, and has responded to internal political pressure accordingly by importing curricula from its more progressive counterparts. However, this approach has not proven to be scientifically sound, as the best fitting curriculum should be socio-culturally and contextually appropriate. As China's social and cultural history has taught us invaluable lessons about the experimentation with ECC reform in the past, it is time to apply these lessons to strengthen the Chinese cultural contribution and develop an innovative Chinese version of ECC. Yet, this endeavour is not without challenge; it will inevitably require time, commitment and resources to make not only ideological but pedagogical shifts. First, Chinese teachers and scholars need to depart from the robotic practice of importing curriculum models from other cultures. In addition, policy-makers and reform leaders should consider the sociocultural appropriateness of any new initiatives when planning ECC reforms. This does not necessarily mean that we should stop learning from others, rather that we must do so bearing in mind our own unique sociocultural realities. Thus, we conclude that culturally universal educational practices should be avoided, and that cultural differences should be considered instead. As such, adapting rather than adopting curriculum models directly from other cultures is vital for the ultimate and possibly long-term implementation success of ECC reform in China (Li et al. 2012). This strategy is, perhaps, the most important lesson we can learn from analysing the social and cultural experimentation involved in the reform of the ECC in China over the past century.

In this study, we have offered glimpses into the nature of ECE in China by examining its curriculum reform process. In particular, in analysing the three major waves of ECC reform in 
China, we have addressed our original research queries by providing insights into: (1) how the ECC has evolved and been revolutionised over time; and (2) how the local culture has interacted with global influences to inform the development and changing nature of the ECC. We conclude that China has indeed made innovative changes in developing and revolutionising the ECC by adopting and adapting curriculum models from foreign cultures over the past century. China has also spearheaded efforts in innovating curriculum models for ECE by experimenting with the creation of a sensitive and sensible curriculum that is socio-culturally suited to the Chinese context. We believe that if China is to achieve and maintain a globally competitive edge through education, it will have to continue to create and sustain its own innovative ECC models to suit its own unique social and cultural conditions. 


\section{References}

Chen, J. J.-L. 2005. "Relation of Academic Support from Parents, Teachers, and Peers to Hong Kong Adolescents’ Academic Achievement: The Mediating Role of Academic Engagement." Genetic, Social, and General Psychology Monographs 131 (2): 77-127.

Chen, J. J.-L. 2007. How the Academic Support of Parents, Teachers, and Peers Contributes to a Student's Achievement: The Case of Hong Kong. Lewiston, NY: Edwin Mellen Press.

Chen, J. J., H. Li, and J. Wang. In press. "Implementing the Project Approach: A Case Study of Hybrid Pedagogy in a Hong Kong Kindergarten. Journal of Research in Childhood Education.

Conrad, C. 2001. "Social History." In International Encyclopedia of the Social and Behavioral Sciences, edited by N. J. Smelser and P. B. Baltes, Vol. 12, 14299-14306. Oxford, UK: Elsevier Science.

LeBaron, M. 2003. Culture and Conflict: Beyond Intractability.” In Conflict Information Consortium, edited by G. Burgess and H. Burgess. Boulder, CO: University of Colorado. http://www.beyondintractability.org/essay/culture-conflict

Li, H. 2004. Story Approach to Integrated Learning. Hong Kong: Oxford University Press.

Li, H. 2005. Developing School-based Curriculum in Hong Kong Kindergartens: Insights, Challenges and Solutions. Hong Kong: The Hong Kong Institute of Education.

Li, H. 2007a. Story Approach to Integrated Learning: The Curricula and Pedagogies. Hong Kong: Oxford University Press.

Li, H. 2007b. Universalism versus Relativism: Cultural Reflections on the ECE Reforms in China. Shanghai: East China Normal University. 
Li, H. 2009. “Kindergarten.” In Encyclopedia of Modern China, Vol. 4, edited by D. Pong, 476-479. Detroit, MI: Charles Scribner's Sons.

Li, H. 2013. "Review of the Reform Plans to Solve the Salary Problem of Kindergarten Teachers in Mainland China.” Early Childhood Education (Educational Sciences) 573 (1/2):

$12-15$.

Li, H. and N. Rao. 2005. "Curricular and Instructional Influences on Early Literacy Attainment: Evidence from Beijing, Hong Kong and Singapore.” International Journal of Early Years Education 13 (3): 235-253.

Li, H., N. Rao, and S. K. Tse 2012. “Adapting Western Pedagogies into Teaching Chinese Literacy: Case Studies of Hong Kong, Shenzhen and Singapore Preschool Classrooms. Early Education and Development 23 (4): 1-19.

Li, H., and X. C. Wang. 2008. "Transformation of Public Kindergartens in Shenzhen: Internet Study of Public Views." Chinese Education and Society 41 (2): 41-70.

Li, H., X. C., Wang, and J. M. S. Wong. 2011. "Early Childhood Curriculum Reform in China: Perspectives from Examining Teachers' Beliefs and Practices in Chinese Literacy Teaching." Chinese Education and Society 44 (6): 5-23.

Liu, Y. and X. X. Feng. 2005. "Kindergarten Educational Reform During the Past Two Decades in Mainland China: Achievements and Problems." International Journal of Early Years Education 13 (2): 93-99.

Ministry of Education. 1952. Interim Regulation on Kindergarten. Beijing: Ministry of Education.

Ministry of Education. 1952. Provisional Regulation on Kindergarten Curriculum. Beijing: Ministry of Education. 
Ministry of Education. 1979. Guidelines on Kindergarten Education (Draft). Beijing: Ministry of Education.

Ministry of Education 1989. Regulations on Kindergarten Education Practice. Beijing: Ministry of Education.

Ministry of Education. 2001. Guidelines for Kindergarten Education Practice - Trial Version. Beijing: Ministry of Education.

Rao, N., S. S. N., Ng, and E. Pearson. 2010. "Preschool Pedagogy: A Fusion of Traditional Chinese Beliefs and Contemporary Notions of Appropriate Practice.” In Revisiting the Chinese Learner: Changing Contexts, Changing Education edited by C K. K., Chan and N. Rao, 255-280. Hong Kong: The University of Hong Kong, Comparative Education Research Centre/Springer Academic.

Tobin, J. 2005. “Quality in Early Childhood Education: An Anthropologist's Perspective.” Early Education and Development 16 (4): 421-434.

Triandis, H. C. 2000. "Culture and Conflict.” International Journal of Psychology 35 (2): 145-152.

Wang, J. and S. Mao. 1996. "Culture and the Kindergarten Curriculum in the People's Republic of China." Early Child Development and Care 123 (1): 143-156.

Wang, X. C. and B. Spodek. 2000. "Early Childhood Education in China: A Hybrid of Traditional, Communist, and Western Culture." Paper presented at the annual meeting of the National Association for the Education of Young Children, Atlanta, GA.

Zhu, J. X. 2015. "Early Childhood Education and Relative Policies in China." http://www.zhujx.com/zh_cn-100-225.html. 
Zhu, J. X. and X. C. Wang. 2005. “Contemporary Early Childhood Education and Research in China." In Contemporary Perspectives in Early Childhood Education: International Perspectives, edited by B. Spodek and O. N. Saracho, Vol. 7, 55-77. Greenwich, CT: Information Age.

Zhu, J. X. and J. Zhang. 2008. "Contemporary Trends and Developments in Early Childhood Education in China.” Early Years: An International Research Journal 28 (2): 173-182. 